\title{
Application of 3D printing and distributed manufacturing during the first-wave of COVID-19 pandemic. Our experience at a third-level university hospital
}

Rubén Perez-Mañanes ${ }^{1,2,3,4^{*}}$ (D), Sonia García-de San José ${ }^{1,5}$, Manuel Desco-Menéndez ${ }^{1,4,6}$, Ignacio Sánchez-Arcilla $a^{1,7}$, Esmeralda González-Fernández ${ }^{1,8}$, Javier Vaquero-Martín' 2,3,4, Javier Pascau González-Garzón 1,6,4,

Lydia Mediavilla-Santos ${ }^{2}$, Diego Trapero-Moreno ${ }^{1}$ and José Antonio Calvo-Haro 1,2,3,4

\begin{abstract}
Background: 3D printing and distributed manufacturing represent a paradigm shift in the health system that is becoming critical during the COVID-19 pandemic. University hospitals are also taking on the role of manufacturers of custom-made solutions thanks to 3D printing technology.

Case Presentation: We present a monocentric observational case study regarding the distributed manufacturing of three groups of products during the period of the COVID-19 pandemic from 14 March to 10 May 2020: personal protective equipment, ventilatory support, and diagnostic and consumable products. Networking during this period has enabled the delivery of a total of 17,276 units of products manufactured using 3D printing technology. The most manufactured product was the face shields and ear savers, while the one that achieved the greatest clinical impact was the mechanical ventilation adapters and swabs. The products were manufactured by individuals in 57.3\% of the cases, and our hospital acted as the main delivery node in a hub with 10 other hospitals. The main advantage of this production model is the fast response to stock needs, being able to adapt almost in real time.

Conclusions: The role of 3D printing in the hospital environment allows the reconciliation of in-house and distributed manufacturing with traditional production, providing custom-made adaptation of the specifications, as well as maximum efficiency in the working and availability of resources, which is of special importance at critical times for health systems such as the current COVID-19 pandemic.
\end{abstract}

Keywords: 3D printing, distributed manufacturing, POC manufacturing, COVID-19, personal protective equipment, face shields, ear savers, ventilatory support, swabs

\footnotetext{
* Correspondence: rubenperez.phd@gmail.com

'Advanced Planning and 3D Manufacturing Unit, Hospital General Universitario Gregorio Marañón, Madrid, Spain

${ }^{2}$ Department of Orthopaedic Surgery and Traumatology, Hospital General Universitario Gregorio Marañón, Madrid, Spain

Full list of author information is available at the end of the article
}

C C The Author(s). 2021 Open Access This article is licensed under a Creative Commons Attribution 4.0 International License, which permits use, sharing, adaptation, distribution and reproduction in any medium or format, as long as you give appropriate credit to the original author(s) and the source, provide a link to the Creative Commons licence, and indicate if changes were made. The images or other third party material in this article are included in the article's Creative Commons licence, unless indicated otherwise in a credit line to the material. If material is not included in the article's Creative Commons licence and your intended use is not permitted by statutory regulation or exceeds the permitted use, you will need to obtain permission directly from the copyright holder. To view a copy of this licence, visit http://creativecommons.org/licenses/by/4.0/ The Creative Commons Public Domain Dedication waiver (http://creativecommons.org/publicdomain/zero/1.0/) applies to the data made available in this article, unless otherwise stated in a credit line to the data. 


\section{Background}

The exponential demand for technical and human resources caused by the COVID-19 pandemic has challenged public health, healthcare organization and hospital care, bringing health systems in many countries to the brink of collapse, with the added difficulty of coping with chronic shortages of personal protective equipment (PPE) and other essential medical supplies [1]. These problems, accentuated both by relocation and by the reduction in business activity due to a lack of supplies from abroad, have shown that it is necessary to have certain manufacturing capacities for the production and equitable supply of essential products, which are crucial for saving lives, as well as for curbing the socioeconomic impact [2].3D printing is a technology that can lead this change in the manufacturing paradigm. It allows the design to be made anywhere in the world because the product as such moves in a digital format to any place, just by printing it with a $3 \mathrm{D}$ printer [3]. In this context of distributed manufacturing, the fact that products are obtained from the same machine at a fixed and predictable cost makes it possible to print at a location close to the end user, ensuring that they arrive in the shortest possible time [4]. The expiration of patents related to different 3D printing technologies such as FDM (Fused Deposition Modeling), the existence of new digital and social platforms, the possibility of collaborative projects ("crowdfunding"), and socio-cultural movements such as the Maker movement [5], have allowed people not only to consume, but also to make and share. Access to this technology during the pandemic has made it easier for professionals and patients, with the aim of seeking to improve people's health, to react to the shortage of equipment by promoting new production models that can quickly respond to a situation of complete uncertainty in health action with regard to such basic issues as transmission, lethality and ethical questions regarding the prioritisation of resources.

In these new production models, university hospitals can act as manufacturing centers using in-house 3D printing technology and distributed production, are part of hubs that allow them to reconcile in-house manufacturing and outsourcing services, strengthening collaborative work and ensuring that this type of manufacturing becomes the standard of care [6-9] and being able to efficiently adjust their resources, objectively identifying their limitations and creating external partnerships. New production models such as point-of-care manufacturing are contemplated, and this makes it possible to respond to needs for space or expensive facilities, to bring together the technical competence profile in industrial aspects, or to keep its portfolio of services up to date without depending on the obsolescence of machines and manufacturing materials, which is very rapid for this type of technology [6].

The aim of this case study is to identify the role of $3 \mathrm{D}$ printing technology in our university hospital during the first wave of the current COVID-19 pandemic.

\section{Case presentation}

This is an observational, descriptive, monocentric case study that includes all the projects developed from the Advanced Planning and 3D Manufacturing Unit (UPAM3D) of the Hospital General Universitario Gregorio Marañón (Madrid, Spain) during the confinement period, as a consequence of the declaration of the state of alarm decreed in the country by the COVID-19 pandemic, between March 14 and May 10, 2020.

The following variables have been analyzed:

- Product type $=$ Final product delivered .

- Number $=$ Number of units of each of the final products delivered.

- Type of supplier = Manufacturers of the products.

- Type of delivery = Donation or purchases, referring to the delivery of the products made by the supplier, either donated or acquired by the hospital through a public purchase process.

- Date $=$ Date of delivery of the final product to the place of destination.

- Destination= Place of delivery of the final product.

The variables have been described as number and percentage.

Networking during this period has enabled the delivery of a total of 17,276 units of products manufactured using 3D printing technology. (Fig. 1) All models manufactured had an end-use. Requirements were communicated to our laboratory on a daily basis and printed inhouse or by external equipment according to availability and volume required. The models had a very intuitive use in most cases, or very technical use in some cases, such as adapters for ventilation systems.

End products delivered can be divided into three main groups:

1. Protection and prevention systems (Fig. 2). This group includes the manufacture of face shields, 3D printed photophore accessories, ear savers, hands-free door openers, or prototypes of masks.

2. Products for Ventilatory Support Therapies (Fig. 3). The peak of hospital admissions due to the pandemic has caused a great demand for ventilation machines, with the consequent transitory lack, so we decided to modify non-sanitary material and sanitary material approved for other uses. This has allowed us to perform non-invasive treatment in those patients who needed 


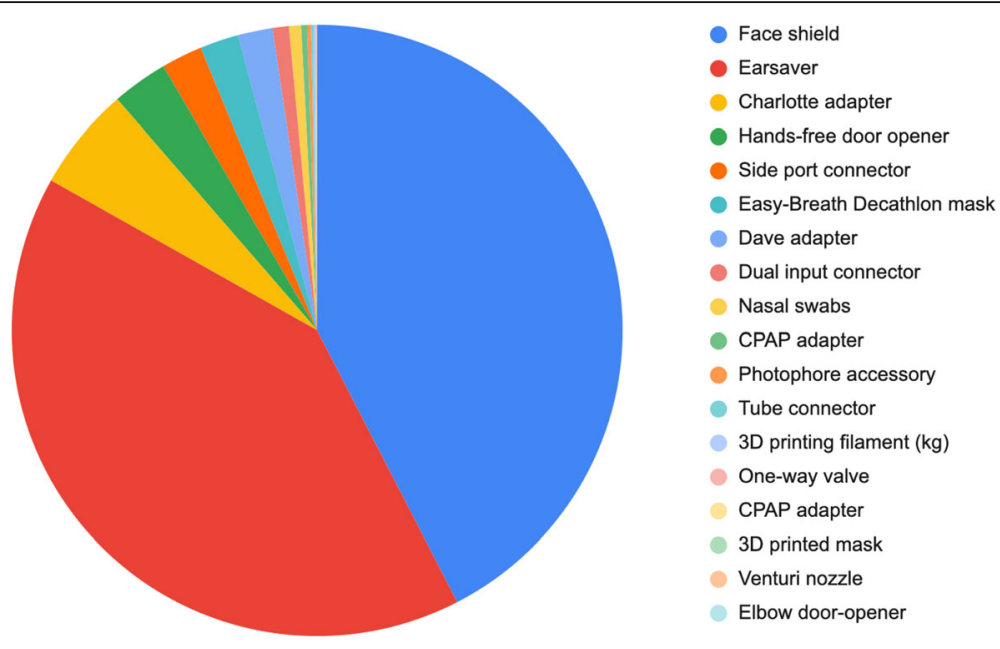

Fig. 1 Products delivered

respiratory support but not without sufficient stock of approved devices. In our center we have used the Easybreath $^{\circ}$ (Decathlon, France) diving mask system modified as a CPAP system (EASY-CPAP), having been necessary the acquisition of masks [10-13], the production of connector parts or supports, and the optimization of the design of other parts adding modifications to adapt it to the existing material in our center. Among the products manufactured, we have included connection parts for the masks and other parts for the ventilation systems such as straight connectors, connectors with side port for oxygen therapy or adapters for positive protection systems.

3. Diagnostic products and consumables (Fig. 4). This group includes the manufacture of swabs of different designs to perform the nasopharyngeal smears necessary for the diagnosis of SARS-CoV-2 infection by PCR test. The advantage of this type of swab has been validated for clinical use [14]. The geometry of the head, the length of the handle and the position of the stigma are configurable elements that have been adapted to the different formats of the container tubes available in our Centre. Considered as a class IIa medical device and manufactured by means of stereolithography technology (SLA) with biocompatible light-curing resin, it is presented in sterile packaging in bags of 10 units and in unitary peel-packs adjusted to local needs.

Desktop 3D printing machines such as the Ultimaker S5 (Utrecht, Netherlands) or the Formlabs Form 2 (Massachusetts, USA) were used to allow decentralised, massively parallel and economic production of the devices in the pandemic environment. The following additive manufacturing technologies were used:
- FDM (Fused Deposition Modeling) in PLA plastic (24\$ per kilogram). This is the most readily available technology and simple technology used for the majority of the products that don't have further requirements.

- SLA (Stereolithography) with engineering resins (175\$ per kilogram) for the parts that were required to be airtight, because of the improved resolution, density and surface finish; and Class IIa biocompatible resin (Formlabs' BioMed Amber Resin; 300\$ per kilogram) for the nasal swabs.

The products were mainly manufactured by individuals $(57.3 \%)$, universities $(7.6 \%)$ or associations $(2.8 \%)$. Manufacturing companies have made $28 \%$ of the products, and the rest (4.3\%) have been achieved through inhouse manufacturing, in this last case being mostly prototypes and product validations.

The products have been donations in $78.2 \%$ of the cases. However, if a greater quantity and optimisation of the production times of a product has been required due to care needs, the acquisition has been made through public purchase. This is the case of face shields or some of the products for ventilatory support, with the purchase of $49 \%$ of the $3 \mathrm{~d}$ printed face shields, $63 \%$ of the Charlotte adapters, $48 \%$ of the side port connectors and $8 \%$ of the Dave adapters.

The delivery date of the products started on March 25th and has been extended until the last day of the study period. Since the beginning of the period, production has been adapted to the demand made by the services in charge of both the availability, coordination and logistics of the personal protective equipment and the 


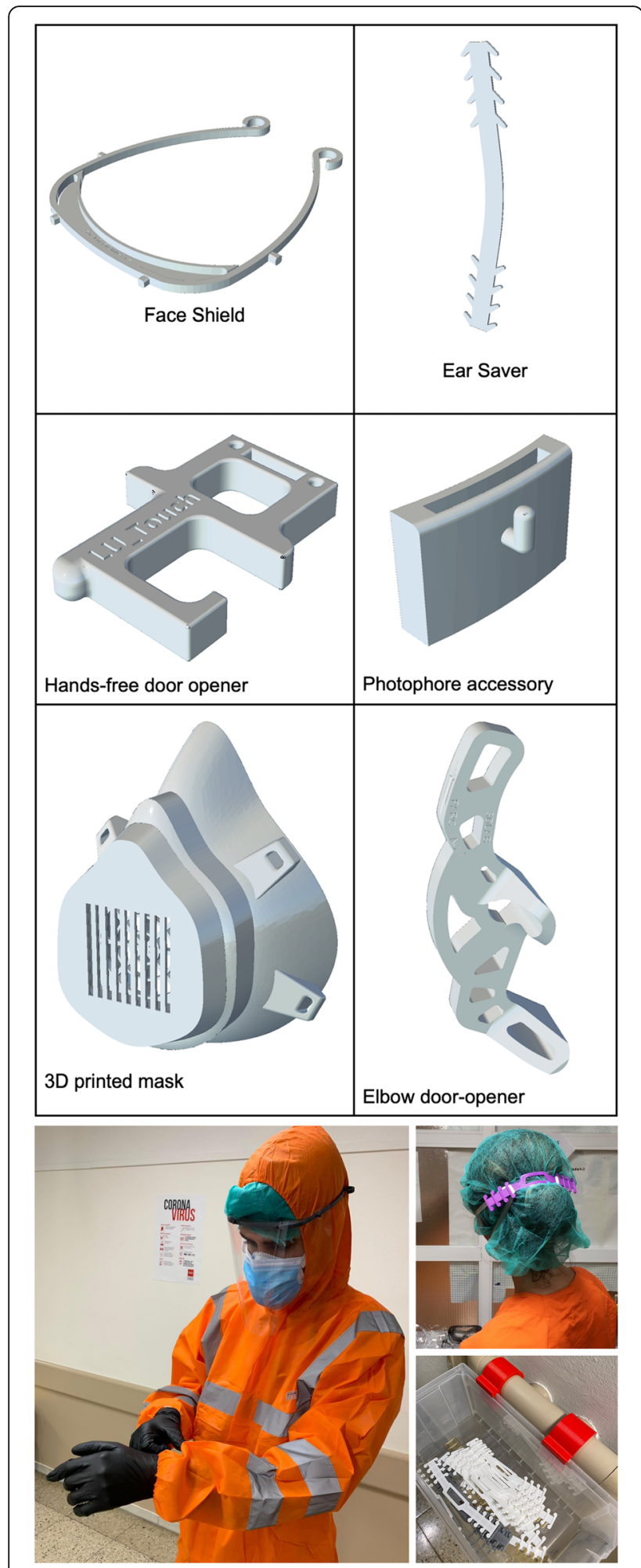

Fig. 2 Images from the STL files and pictures of protection products
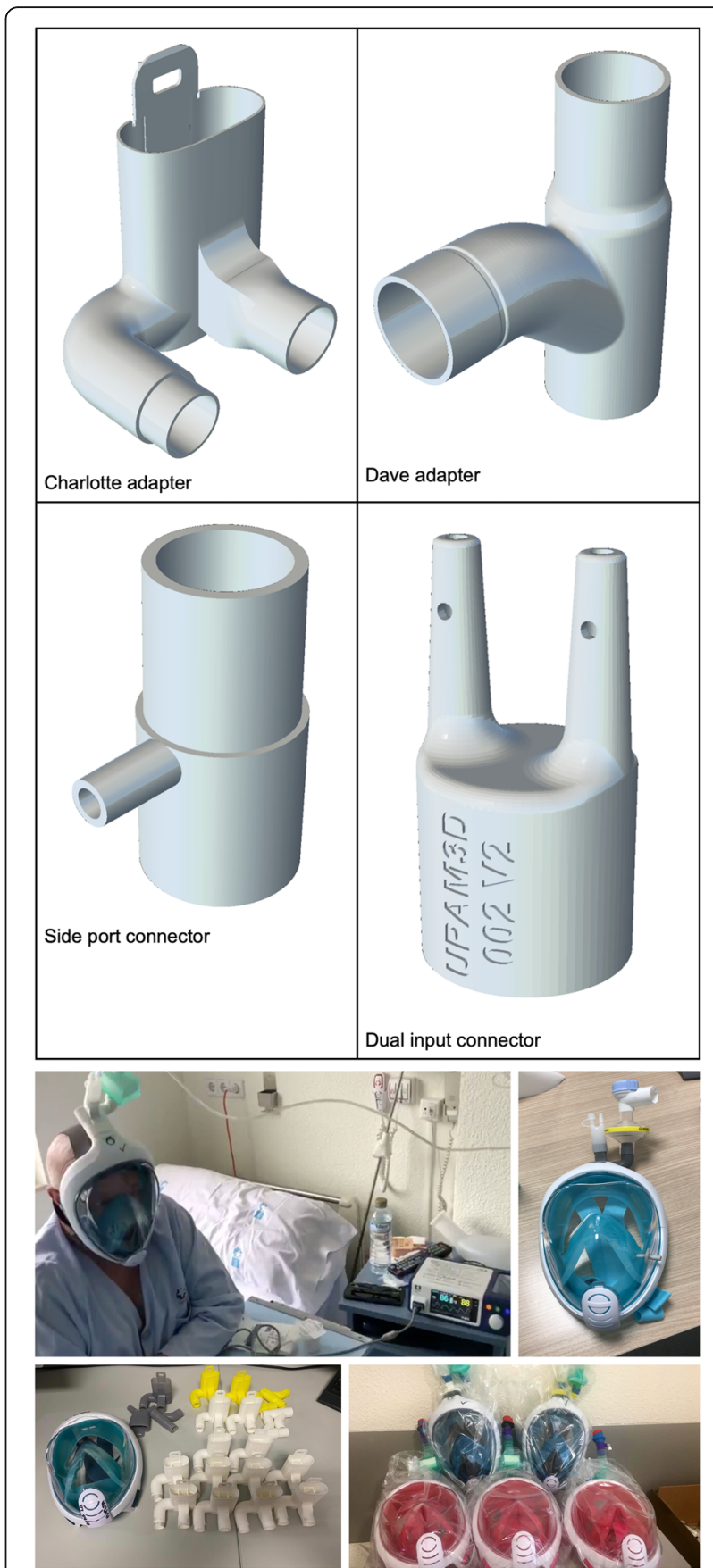

Fig. 3 Images from the STL files and pictures of ventilation products

care needs of the clinical services involved in the ventilatory support therapies. Thus, during the first week $83.7 \%$ of the face shields had already been delivered. However, the demand for other products has been later, such as the connectors for ventilatory support delivered from 31st March, or the ear savers whose first delivery was made on 14th April.

The destination of the products delivered was the Centre itself in $90.9 \%$ of the cases, although the 


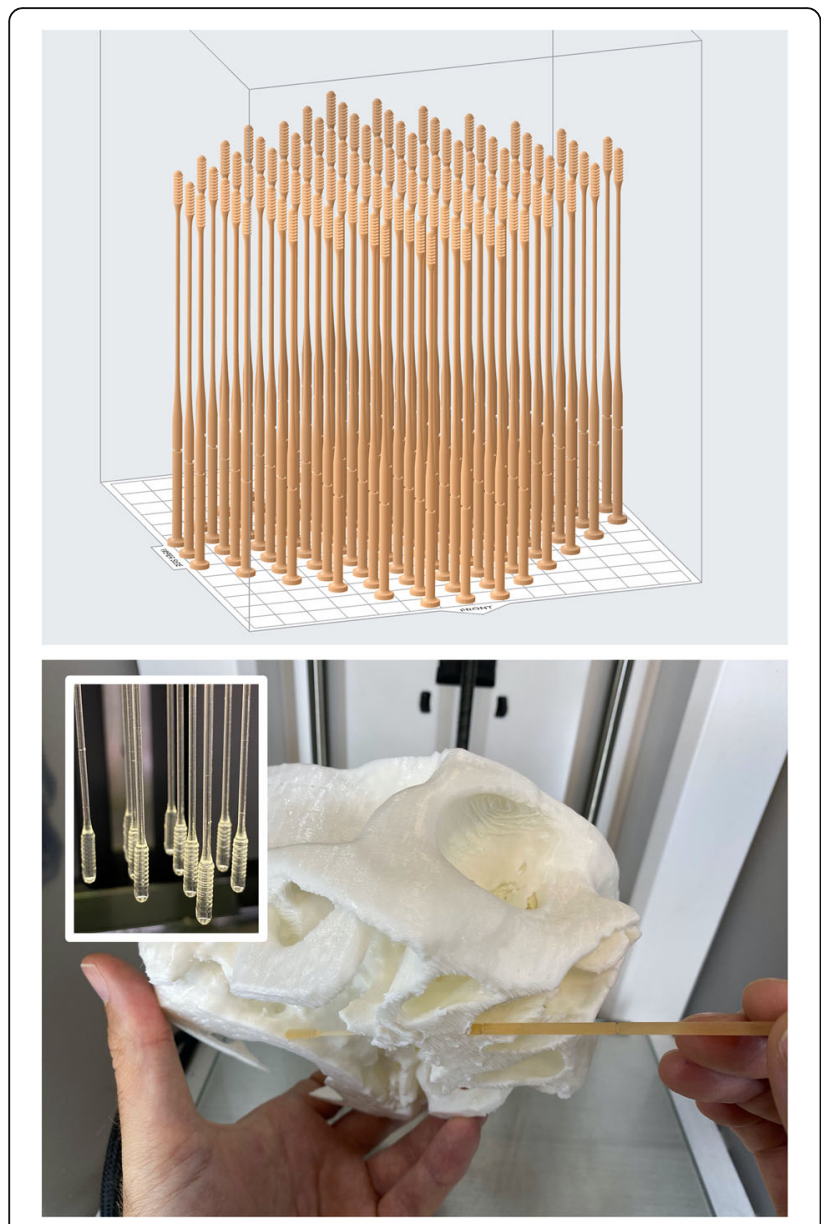

Fig. 4 Images from the STL files and pictures of 3D printed swabs

production capacity, together with the demand caused by the global shortage, made it possible to deliver products to other Centres (Table 1).

Regarding quality control, parts were collected from the producer network by couriers sent from the Hospital, where assembly (if needed), quality check and delivery to the users was centralised. Each delivery was checked at the arrival, parts counted and noted. In addition, a second check was performed before assembly.

\section{Discussion and conclusions}

The integration of 3D printing technology in the healthcare process allows for the monitoring of the end-to-end process, from the design and validation for clinical use of different products to the optimized production of these products adapted to the healthcare need, which is of great importance in health systems during periods of sanitary crisis such as the COVID-19 pandemic, when the shortage of healthcare resources at a global level makes universal availability and coverage impossible.
The manufacturing university hospital is not born as a competition of the factories or the traditional medical industry, but it generates value in personalized medicine by gathering the professional team and the necessary resources to be able to treat by means of a personalized medical product with the maximum guarantees of quality and commitment to the patients, generating knowledge based on each individual experience, and thus allowing a qualitative leap in exponential patientcentered medicine.

Hospital General Universitario Gregorio Marañón is a pioneer in the transversal implementation of $3 \mathrm{D}$ printing at a hospital level, incorporating an advanced planning and POC manufacturing unit integrated as an in-house $3 \mathrm{D}$ printing laboratory in the care flow of more than 20 medical-surgical specialties. Our 3D printing laboratory was founded in 2015, initially manufacturing biomodels with FDM technology, and later surgical guides in resin using SLA technology. As a manufacturer, the hospital is licensed for the manufacture of medical devices and certified by the international standard ISO 13485 for Quality Management Systems for medical devices. This role as a manufacturing hospital has enabled networking and coordination in production with other hospitals and with associations, institutions or individuals with the possibility of printing products previously validated from the Centre according to care needs. In a manufacturing university hospital, 3D printing goes hand in hand with teaching and translational research, acting as an accelerator of clinical innovation and enabling advanced rapid prototyping, reducing verification and validation times. This has been the case with surgical masks or some of the parts manufactured for ventilatory support systems [15].

The appearance of different socio-cultural movements such as Coronavirusmakers [16] and collaborative networks such as the one created by the Parc Taulí Foundation [8], making available different products with the technical design specifications, material requirements and printing parameters, have made it possible to optimise the production of some of these products such as the Charlotte and Dave adapters, and other connectors and valves. Sharing this new paradigm, at the UPAM3D of our hospital we have designed and validated the clinical utility of some products such as face shields, connections that facilitate double oxygen inlet, or adaptation pieces for positive pressure ventilation systems, publishing the designs available to the community (Table 2).

The disinterested offer of the different actors to participate in this type of production has made it possible both to cover the intrahospital demand and to collaborate with other centres, even at times when the need for specific products has required an increase in production. 
Table 1 Types of products delivered to other Centres

\begin{tabular}{llll}
\hline Destination & $\begin{array}{l}\text { Charlotte } \\
\text { adapter }\end{array}$ & $\begin{array}{l}\text { Face } \\
\text { Shields }\end{array}$ & $\begin{array}{l}\text { Total } \\
\text { amount }\end{array}$ \\
$\begin{array}{l}\text { Hospital Santa Cristina (Madrid) } \\
\text { Clínica Ruber (Madrid) }\end{array}$ & 475 & 475 \\
$\begin{array}{l}\text { Hospital Infanta Elena } \\
\text { Valdemoro) }\end{array}$ & 349 & 349 \\
$\begin{array}{l}\text { Centro de Salud Maqueda } \\
\text { (Madrid) }\end{array}$ & 120 & 120 \\
$\begin{array}{l}\text { Hospital Montecelo (Vigo) } \\
\begin{array}{l}\text { Clínica Universidad de Navarra } \\
\text { (Madrid) }\end{array}\end{array}$ & 100 & 101 \\
$\begin{array}{l}\text { Hospital Beata María Ana } \\
\text { (Madrid) }\end{array}$ & 100 & 100 \\
$\begin{array}{l}\text { Hospital La Princesa (Madrid) } \\
\text { Hospital del Sureste (Arganda) }\end{array}$ & 22 & 50 & 50 \\
Hospital Alcorcón (Alcorcón) & 20 & & 22 \\
\begin{tabular}{l} 
Total amount \\
\hline
\end{tabular} & $\mathbf{6 2}$ & $\mathbf{1 2 9 5}$ & $\mathbf{1 3 5 7}$ \\
\hline
\end{tabular}

It is interesting to note that the first products are delivered 11 days after the start of the alarm period. This is justifiable because in the first days of the study period, and in the face of a minor casuistry, the demand for products was also lower. In those first days, the activity as a manufacturing university hospital consisted of designing and validating prototypes as well as identifying collaborators for the constitution of a distributed production network (Fig. 5), so that incidents in terms of need and/or supply could be minimized with the most agile response possible. Thus, after 7 days, the first face shields units were manufactured and delivered under the coordination of the Services responsible for occupational risk prevention. An internal validation of the design was carried out, and after assessing the benefit-risk in the areas with more limited resources, the distribution was staggered. Something similar has occurred in the manufacture of parts for ventilatory support: when the lack and difficulty of supply from the different Clinical Services is identified, it is reported to the UPAM3D from where action is coordinated not only to respond to the high demand, but also for rapid prototyping or design improvements. The production offer of a large number

Table 2 Name of products (rows) and file URL (columns)

\begin{tabular}{|c|c|c|}
\hline $\begin{array}{l}\text { 3D printed } \\
\text { product }\end{array}$ & Author & Download link \\
\hline Face Shield & UPAM3D & https://www.thingiverse.com/thing:4258101 \\
\hline Ear Saver & UC3M & $\begin{array}{l}\text { https://github.com/roboticslab-uc3m/covid19-fablab/blob/a6568a7eb4245d05b8781 } 16 \\
\text { 9d61f92aae42d1035/SujetaMascarillasUC3M.stl }\end{array}$ \\
\hline $\begin{array}{l}\text { Charlotte } \\
\text { adapter }\end{array}$ & $\begin{array}{l}\text { Hospital de Gardone Valtrompia, ISIN } \\
\text { NOVA }\end{array}$ & https://www.isinnova.it/easy-covid19-esp-2/ \\
\hline $\begin{array}{l}\text { Hands-free door } \\
\text { opener }\end{array}$ & Lupeon SL & https://lupeon.com/2020/03/lu-touch/ \\
\hline $\begin{array}{l}\text { Side port } \\
\text { connector }\end{array}$ & Hospital Parc Taulí & $\begin{array}{l}\text { http://www.tauli.cat/es/institut/plataformes-i-serveis/laboratori-3d/covid-3d/cataleg/ } \\
\text { \#3dpt012 }\end{array}$ \\
\hline Dave adapter & $\begin{array}{l}\text { Hospital de Gardone Valtrompia, ISIN } \\
\text { NOVA }\end{array}$ & https://www.isinnova.it/easy-covid19-esp-2/ \\
\hline $\begin{array}{l}\text { Dual input } \\
\text { connector }\end{array}$ & UPAM3D & https://www.thingiverse.com/thing:4282537 \\
\hline CPAP adapter & UPAM3D & https://www.thingiverse.com/thing:4282700 \\
\hline Tube connector & UPAM3D & https://www.thingiverse.com/thing:4282640 \\
\hline Swabs & $\begin{array}{l}\text { Hospital Virtual Valdecilla } \\
\text { University of South Florida's (USF) } \\
\text { Department of Radiology }\end{array}$ & $\begin{array}{l}\text { https://www.hvvaldecilla.es/proyectos/recogidas-de-muestras-hisopos/ } \\
\text { 3dclinicalapplications@usf.edu }\end{array}$ \\
\hline One-way valve & Hospital Parc Taulí & $\begin{array}{l}\text { http://www.tauli.cat/es/institut/plataformes-i-serveis/laboratori-3d/covid-3d/cataleg/ } \\
\text { \#3dpt023 }\end{array}$ \\
\hline $\begin{array}{l}\text { Photophore } \\
\text { accessory }\end{array}$ & Hospital Virtual Valdecilla & https://www.hvvaldecilla.es/proyectos/accesorio-para-fotoforos/ \\
\hline Mask & Cagriahiskali & $\begin{array}{l}\text { https://cults3d.com/en/3d-model/tool/covid-19-mask-easy-to-print-no-support-modified- } \\
\text { version }\end{array}$ \\
\hline Venturi Nozzle & Mothy & https://www.thingiverse.com/thing:4231890 \\
\hline $\begin{array}{l}\text { Elbow door- } \\
\text { opener }\end{array}$ & Hospital Parc Taulí & $\begin{array}{l}\text { http://www.tauli.cat/es/institut/plataformes-i-serveis/laboratori-3d/covid-3d/cataleg/ } \\
\text { \#3dpt002 }\end{array}$ \\
\hline
\end{tabular}




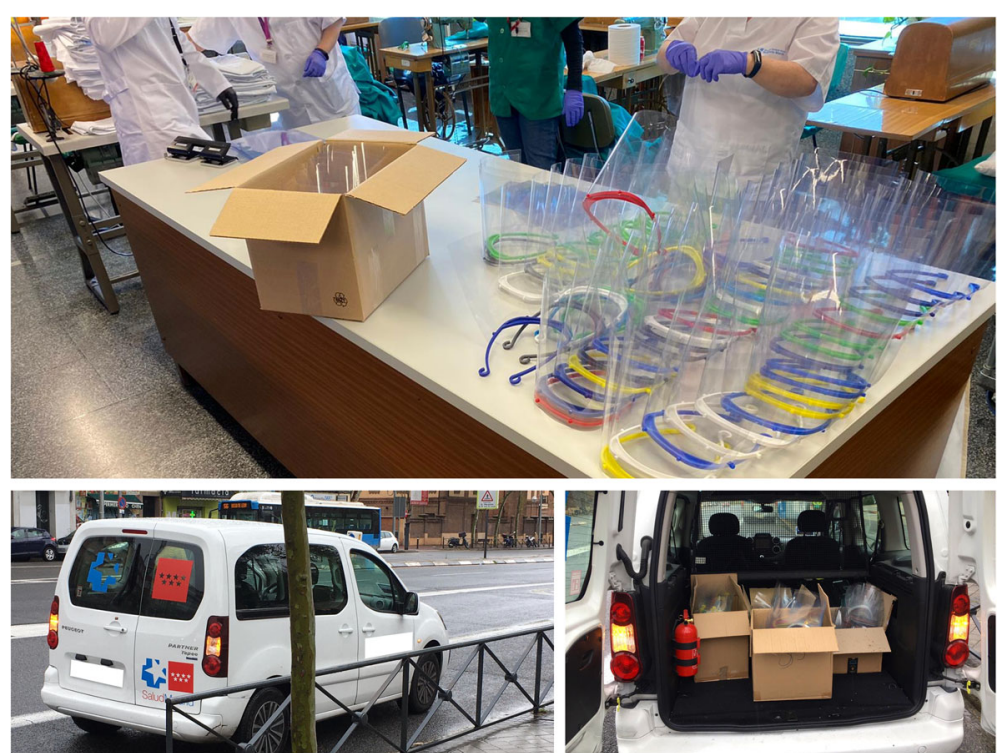

Fig. 5 Example of distributed production. Hospital General Universitario Gregorio Marañón

of participating actors has facilitated the maintenance of the rhythm of production and collaborative work with other Centres, also allowing a staggered delivery and adjusted in real time to the demand.

During the first wave of the pandemic we had to apply emergency solutions, where the vocation and personal effort were essential. Given the exorbitant prices of products with very low stock at that time, the general feeling was one of great speed of response and access to a large number of products at a very low cost, although a cost-economic analysis is not available because it was an exceptional situation where any comparative reference price had not been extrapolated.

Although there are multiple benefits related to POC manufacturing, and even being very significant the contribution in terms of internal knowledge generation, customization, local quality control and cost reduction; we undoubtedly want to highlight the response times as the main advantage over traditional manufacturing and distribution. During this first wave of the pandemic, the pace of manufacturing and the minimum delay with the commissioning, the scalability of production and the capacity of adaptation to the exponential increase experienced, have been key factors in placing this health product manufacturing paradigm in a preferential position within the health system.

In spite of the limitation of being a descriptive case study conditioned by the activity of a third-level university hospital with a very high casuistry of patients affected by COVID-19, which has forced a restructuring of the Centre at all levels [17], the results obtained reflect that the role of the manufacturing hospital allows the reconciliation of in-house and distributed manufacturing with traditional production, providing custom-made adaptation of the specifications, as well as maximum efficiency in the working and availability of resources, which is of special importance at critical times for health systems such as the current COVID-19 pandemic.

\section{Abbreviations}

3D: Three dimensional; COVID-19: Coronavirus disease 2019;

CPAP: Continuous positive airway pressure; FDM: Fused deposition modeling; ISO: International Organization for Standardization; SARS-CoV-2: Severe acute respiratory syndrome coronavirus 2; PCR: Polymerase chain reaction; POC: point of care; PPE: Personal protective equipment;

SLA: Stereolithography

\section{Acknowledgments}

We would like to thank all the workers at the Hospital General Universitario Gregorio Marañón for their selfless help during the difficult weeks of the peak of the COVID-19 pandemic. Very special thanks to all the healthcare personnel for their dedication and great professionalism shown at all times. Thanks to the individuals who offered their 3D printed products from the very beginning and to the companies who have collaborated with their donations and their time.

\section{Authors' contributions}

RPM and JACH conceived the idea of the study, RPM, SGSJ, MDM, ISA, EGF, JVM, and JACH contributed to the study design, LMS and DTM performed the statistical analysis, SGSJ, JPGG, RPM, and JACH took part in the interpretation of the results and JPGG, JACH, and RPM critically revised manuscript drafts. All authors read and approved the final version of the manuscript.

\section{Funding}

Supported by Project Pl18/01625 (Ministerio de Ciencia, Innovación y Universidades, Instituto de Salud Carlos III and European Regional 
Development Fund "Una manera de hacer Europa"). Funds have been allocated from this project for support and maintenance of the 3D printing laboratory.

\section{Availability of data and materials}

All data analyzed during the current case study are available from the corresponding author on reasonable request. The $3 \mathrm{D}$ files are available in the download links included in this paper.

\section{Declarations}

\section{Ethics approval and consent to participate}

The authors state that no experiments on humans or animals have been conducted for this research. They have followed their Center's protocols on the publication of patient data. Patient data do not appear in this article and that they are in possession of the patients' informed consent for participation in the study and publication of the results.

\section{Consent for publication}

Not applicable.

\section{Competing interests}

The authors declare that they have no competing interest.

\section{Author details}

'Advanced Planning and 3D Manufacturing Unit, Hospital General Universitario Gregorio Marañón, Madrid, Spain. ${ }^{2}$ Department of Orthopaedic Surgery and Traumatology, Hospital General Universitario Gregorio Marañón, Madrid, Spain. ${ }^{3}$ Faculty of Medicine. Department of Surgery, Universidad Complutense, Madrid, Spain. ${ }^{4}$ Instituto de Investigación Sanitaria Gregorio Marañón, Madrid, Spain. ${ }^{5}$ Deputy Hospital Management, Hospital General Universitario Gregorio Marañón, Madrid, Spain. ${ }^{6}$ Department of Bioengineering and Aerospace Engineering, Universidad Carlos III, Madrid, Spain. 'Department of Labour Risks Prevention, Hospital General Universitario Gregorio Marañón, Madrid, Spain. ${ }^{8}$ Supply Management, Hospital General Universitario Gregorio Marañón, Madrid, Spain.

Received: 6 June 2020 Accepted: 28 February 2021

Published online: 08 March 2021

\section{References}

1. Nacoti M, Ciocca A, Giupponi A, Brambillasca P, Lussana F, Pisano M, et al. At the Epicenter of the Covid-19 Pandemic and Humanitarian Crises in Italy: Changing Perspectives on Preparation and Mitigation. NEJM Catalyst. 2020; 2:1-5. https://doi.org/10.1056/CAT.20.0080

2. Bayona E. The pandemic strips the Spanish industry and places the country before the challenge of its reconversion. Diario Público. https://www. publico.es/economia/covid-19-pandemia-desnuda-industria-situa-pais-retoreconversion.html.

3. Wall S. 3D printing: a manufacturing revolution. 2016. https://shanewallcto. com/2016/12/28/3d-printing-a-manufacturing-revolution/

4. Castro N. 3D printing forces rethinking of tariffs. Diario El Mundo. 2016; http://www.elmundo.es/economia/2016/10/04/57f384e8e2704e3d438b462c. html.

5. Marcos Z. The founder of the Maker movement explains the success of 'Do It Yourself'. Diario El País. http://one.elpais.com/fundador-del-movimientomaker-explica-exito-del-hazlo/.

6. Medical Additive Manufacturing 3D Printing. Annual Report 2018. https:// www.sme.org/globalassets/sme.org/media/white-papers-and-reports/2018sme-medical-am3dp-annual-report.pdf

7. Mayo Clinic Anatomical 3D Printing Lab. https://www.mayoclinic.org/es-es/ departments-centers/anatomic-modeling-laboratories/overview/ovc-204 73121

8. 3D Lab Parc Taulí. L'Institut d'Investigació i Innovació Parc Taulí. http://www. tauli.cat/es/institut/plataformes-i-serveis/laboratori-3d/

9. HSS Opening 3D Printing Lab for Complex, Personalized Ortho Implants. 2019. https://news.hss.edu/hss-opening-3d-printing-lab-for-complex-persona lized-ortho-implants/

10. Emergency mask for hospital ventilators. https://www.isinnova.it/easy-covid1 9-eng/
11. De Cesco AF. Coronavirus, the Brescia-based company that turned a snorkel mask into a ventilator. https://www.corriere.it/tecnologia/20 marzo_23/ coronavirus-l-azienda-bresciana-che-ha-trasformato-maschera-snorkeling-unrespiratore-cdf7d0e2-6d14-11ea-ba71-0c6303b9bf2d.shtml?refresh_ce-cp

12. Terrón I. Can dive masks really be used as ventilators? Diario La Razón. https://www.larazon.es/salud/20200404/hx4rlf7ayjd4zbuvi6pm6yunz4.html

13. Marteau S. The scuba mask, second wind at the hospitals. Le Monde. https://www.lemonde.fr/m-le-mag/article/2020/04/11/le-masque-deplongeesecond-souffle-des-hopitaux_6036333_4500055.html

14. Ford, J., Goldstein, T., Trahan, S. et al. A 3D-printed nasopharyngeal swab for COVID-19 diagnostic testing. 3D Print Med 6, 21 (2020). https://doi.org/10.11 86/s41205-020-00076-3.

15. The Gregorio Marañón adapts a sleep apnea device as a breathing support for COVID-19 patients. https://www.europapress.es/madrid/noticia-gregoriomaranon-adapta-aparato-apnea-sueno-soporte-respiratorio-pacientescovid-19-20200407122245.html

16. Forum CoronavirusMakers (A.I.RE.) https://foro.coronavirusmakers.org

17. The 'Marañón miracle' or the multiplication of beds and ICUs. https://elpais. com/espana/madrid/2020-04-16/el-milagro-maranon-o-la-multiplicacion-delas-camas-y-las-uci.html

\section{Publisher's Note}

Springer Nature remains neutral with regard to jurisdictional claims in published maps and institutional affiliations.

\section{Ready to submit your research? Choose BMC and benefit from:}

- fast, convenient online submission

- thorough peer review by experienced researchers in your field

- rapid publication on acceptance

- support for research data, including large and complex data types

- gold Open Access which fosters wider collaboration and increased citations

- maximum visibility for your research: over $100 \mathrm{M}$ website views per year

At $\mathrm{BMC}$, research is always in progress.

Learn more biomedcentral.com/submissions 